\title{
CORRESPONDENCE.
}

\section{ALGEBRAIC EQUATIONS WITH COMPLEX COEFFICIENTS}

To the Editor of the Mathematical Gazette.

Dear Sir, - Can any reader give me, or refer me to, a practical method of finding numerically the roots of an algebraic equation with complex coefficients? This may appear to be an academic question, but actually $I$ have recently met it in connexion with a piece of practical work. For degrees up to 4 ordinary methods of solution will apply, square- or cube-roots of $\alpha+i \beta$ being found trigonometrically; but there are no similar methods for higher degrees. The presence of complex coefficients means that there are roots of the form $\alpha+i \beta$ unaccompanied by the conjugate $\alpha-i \beta$, hence it seems to me-in spite of a statement to the contrary which I have read in a French memoir-that the ordinary root-squaring method is inapplicable since we cannot separate the moduli from the periodically-fluctuating arguments. The only method I am able to suggest is the following : it is admittedly very operose, involving the solution of an equation of doubled degree.

Collect imaginary terms and write the equation in the form

$$
P(x)+i Q(x)=0,
$$

where $P(x)$ and $Q(x)$ are polynomials. Multiplying by $P(x)-i Q(x)$ we get

$$
[P(x)]^{2}+[Q(x)]^{2}=0,
$$

an equation of doubled degree with real coefficients, having conjugate pairs of roots of the form $\alpha \pm i \beta$. These may be found by the rootsquaring method as improved and completed by Brodetsky and Smeal, Proc. Camb. Math. Soc., vol. xxii, p. 83 [1924]. These roots will include those we want and also their unwanted conjugates. The latter can be rejected by substitution and trial : or usually it would be practicable, by a tentative process, to select the roots whose imaginary parts add up to the negative of the imaginary part of the second term in the original equation.

Your obedient servant,

G. J. LIDSTONe.

1055. James I also paid a visit to Tycho Brahe on the island of Hveen, which gave him indescribable pleasure: he believed that in his company he fathomed the marvels of the universe, and lauded the astronomer in spirited Latin verse as the friend of Urania, and as the master of the starry world.-L. von Ranke, History of England, vol. i (Oxford, 1875), p. 367.

1056. Finger Multiplication.

Every lady of the land

Has twenty nails upon each hand

Five and twenty hands and feet

This is true without deceit.

-W. Kerr, The English Apprentice, p. 190. [Per Mr. V. Naylor.] 